\title{
Telomere Length and Bipolar Disorder
}

\author{
Timothy R Powell ${ }^{1,2}$, Danai Dima ${ }^{3,4,5}$, Sophia Frangou ${ }^{*, 5,6}$ and Gerome Breen ${ }^{1,2,6}$ \\ 'Social, Genetic and Developmental Psychiatry, Institute of Psychiatry, Psychology and Neuroscience, King's College London, London, UK; ${ }^{2}$ National \\ Institute for Health Research Biomedical Research Centre for Mental Health, Institute of Psychiatry, Psychology and Neuroscience at the Maudsley \\ Hospital and King's College London, London, UK; ${ }^{3}$ Department of Psychology, City, University of London, London, UK; ${ }^{4}$ Department of \\ Neuroimaging, Institute of Psychiatry, Psychology and Neuroscience, King's College London, London, UK; ${ }^{5}$ Department of Psychiatry, Icahn School of \\ Medicine at Mount Sinai, New York, NY, USA
}

\begin{abstract}
Variation in telomere length is heritable and is currently considered a promising biomarker of susceptibility for neuropsychiatric disorders, particularly because of its association with memory function and hippocampal morphology. Here, we investigate telomere length in connection to familial risk and disease expression in bipolar disorder (BD). We used quantitative PCRs and a telomere-sequence to single-copy-gene-sequence ratio method to determine telomere length in genomic DNA extracted from buccal smears from 63 patients with BD, 74 first-degree relatives (49 relatives had no lifetime psychopathology and 25 had a non-BD mood disorder), and 80 unrelated healthy individuals. Participants also underwent magnetic resonance imaging to determine hippocampal volumes and cognitive assessment to evaluate episodic memory using the verbal paired associates test. Telomere length was shorter in psychiatrically well relatives $(p=0.007)$ compared with unrelated healthy participants. Telomere length was also shorter in relatives (regardless of psychiatric status; $p<0.0 \mathrm{I}$ ) and patients with $\mathrm{BD}$ not on lithium $(p=0.02)$ compared with lithium-treated patients with $\mathrm{BD}$. In the entire sample, telomere length was positively associated with left and right hippocampal volume and with delayed recall. This study provides evidence that shortened telomere length is associated with familial risk for BD. Lithium may have neuroprotective properties that require further investigation using prospective designs.

Neuropsychopharmacology (2018) 43, 445-453; doi:I0.I038/npp.20 I7.125; published online 26 July 2017
\end{abstract}

\section{INTRODUCTION}

Telomeres are DNA repeat structures (TTAGGG) at the end of each chromosome that undergo shortening during mitosis (Allsop et al, 1992; Stewart et al, 2012). Telomere shortening has been associated with exposure to cellular stressors (Saretzki and Von Zglinicki, 2002), lifestyle factors (Valdes et al, 2005), and social adversity (Epel et al, 2004; Gianaros et al, 2007; Shalev et al, 2013), whereas telomerase, an enzyme that adds DNA sequence repeats (TTAGGG) onto the $3^{\prime}$ telomeric end, may reverse or mitigate this process (Allsop et al, 1992; Stewart et al, 2012). Cell senescence or cell death is triggered when a critically short telomere length is reached (Stewart et al, 2012). Telomere length is therefore considered a promising biomarker of biological aging and susceptibility to disease (Calado and Young, 2009; Heidinger et al, 2011).

The relationship between telomere length and psychiatric disorders is a topic of much interest but also uncertainty (Eitan et al, 2014). Previous studies have reported shortened

\footnotetext{
*Correspondence: Professor S Frangou, Department of Psychiatry, Icahn School of Medicine at Mount Sinai, 1425 Madison Avenue, New York, NY 10029, USA, Tel: + I 212659 |668, Fax: 212656 I668,

E-mail: Sophia.frangou@mssm.edu

${ }^{6}$ These two authors contributed equally to this work.

Received II December 2016; revised 6 June 2017; accepted II June 2017; accepted article preview online 16 June 2017
}

peripheral telomere length in major depressive disorder (MDD) (Verhoeven et al, 2016; Hartmann et al, 2010; Lung et al, 2007), schizophrenia (SCZ) (Yu et al, 2008), as well as different forms of dementia (Mouiha et al, 2011; Rabinovici et al, 2007). In bipolar disorder (BD), individual studies have reported both reduced (Barbé-Tuana et al, 2016; Lima et al, 2015) and increased telomere length in patients compared with unrelated healthy individuals (Martinsson et al, 2013; Simon et al, 2006). The heterogeneity of the primary studies is reflected in recent meta-analyses that either failed to find an effect of diagnosis (Colpo et al, 2015) or reported a small effect (Darrow et al, 2016). In post-mortem brain tissue, decreased telomere length has been found in the hippocampus of patients with SCZ, BD, and MDD, suggesting that telomere shortening may be more relevant or pronounced in this brain region (Mamdani et al, 2015).

Telomere length is associated with brain morphology, particularly the hippocampus (King et al, 2014; Nilsonne et al, 2015), a brain region that appears vulnerable to multiple disease mechanisms (Hibar et al, 2016; Rabinovici et al, 2007; Schmaal et al, 2016; van Erp et al, 2016; Mouiha et al, 2011) that is also capable of neurogenesis (Barnes et al, 2009; Spalding et al, 2013). Telomere length is also associated with memory function (Valdes et al, 2010) including episodic memory that is closely linked to hippocampal function (Dickerson and Eichenbaum, 2010; Kühn and Gallinat, 2014; Van Petten, 2004). Telomere shortening may therefore 
Table I Sample Characteristics

\begin{tabular}{|c|c|c|c|c|c|}
\hline & $\begin{array}{l}\text { Patients with BD on lithium } \\
\qquad N=28\end{array}$ & $\begin{array}{l}\text { Patients with BD not on } \\
\text { lithium, } N=35\end{array}$ & $\begin{array}{c}\text { Relatives with psychiatric } \\
\text { diagnoses, } N=25\end{array}$ & $\begin{array}{l}\text { Psychiatrically well relatives } \\
\qquad N=49\end{array}$ & $\begin{array}{l}\text { Unrelated healthy } \\
\text { individuals, } N=\mathbf{8 0}\end{array}$ \\
\hline Age $(\text { years })^{a}$ & $45.53($ ( 0.23$)$ & 42.91 (I0.65) & $30.40(9.84)$ & $36.59(14.74)$ & $39.7 \mid(\mid 4.82)$ \\
\hline Sex, $n$ (\% male) & $13(46.40)$ & $17(48.60)$ & $9(36.0)$ & $23(46.9)$ & $36(45)$ \\
\hline IQ & | $6.30(|4.2|)$ & $121.19(21.48)$ & $108.80(\mid 4.25)$ & | | $8.78(\mid 6.87)$ & $121.82(19.88)$ \\
\hline WMS-VPA: immediate recall & $11.86(1.95)$ & I0.45 (32.26) & $9.23(2.85)$ & $10.97(3.36)$ & $11.92(3.16)$ \\
\hline WMS-VPA: delayed recall & $12.07(1.24)$ & $10.33(2.83)$ & $8.71(4.44)$ & 10.87 (2.85) & $12.18(1.85)$ \\
\hline $\begin{array}{l}\text { Hamilton Depression Rating } \\
\text { Scale }^{b}\end{array}$ & $3.53(4.37)$ & $4.31(4.87)$ & $1.44(2.23)$ & $0.23(0.67)$ & $0.17(0.61)$ \\
\hline Young Mania Rating Scale & $1.17(2.55)$ & $1.17(2.10)$ & $0.32(1.14)$ & $0.04(0.29)$ & $0.15(0.45)$ \\
\hline $\begin{array}{l}\text { Age of onset of bipolar disorder } \\
\text { (years) }\end{array}$ & $24.36(7.33)$ & $26.54(9.27)$ & NA & NA & NA \\
\hline Any medication, $n(\%)^{c}$ & $28(100 \%)$ & $30(85.70)$ & $15(20.27)$ & 0 & NA \\
\hline Any antidepressant $(n)^{d}$ & $15(53.60)$ & $16(45.70)$ & $15(20.27)$ & 0 & NA \\
\hline Any antipsychotic $(n)^{\mathrm{e}}$ & II (39.60) & $13(37.10)$ & 0 & 0 & NA \\
\hline Any anticonvulsant $(n)^{f}$ & $5(17.90)$ & $21(60.00)$ & 0 & 0 & NA \\
\hline Hippocampal volume, left $\left(\mathrm{cm}^{3}\right)$ & $4.4 I(0.55)$ & $4.39(0.49)$ & $4.32(0.61)$ & $4.33(0.6)$ & $4.44(0.60)$ \\
\hline $\begin{array}{l}\text { Hippocampal volume, right } \\
\left(\mathrm{cm}^{3}\right)\end{array}$ & $4.11(0.49)$ & $4.07(0.42)$ & $4.02(0.55)$ & $3.98(0.58)$ & $4.41(0.60)$ \\
\hline
\end{tabular}

Abbreviations: BD, bipolar disorder, IQ, intelligence quotient; VPA, verbal paired associates; WMS, Wechsler Memory Scale-III.

All continuous variables are shown as mean (SD); IQ was derived from the Wechsler Adult Intelligence Scale-Revised; Scaled scores reported for both WMS-VPA measures.

a Relatives < patients and controls: $p<0.03$.

batients $>$ relatives, controls, all $p<0.000$ I.

'59 Patients were prescribed more than one psychotropic.

${ }^{\mathrm{d} A l l}$ antidepressants prescribed were serotonin reuptake inhibitors.

eAll but three antipsychotics prescribed were second-generation agents.

fSodium valproate $=14$; carbamazepine $=5$; lamotrigine $=2$; combinations $=5$. 
represent a common biological mechanism linking hippocampal abnormalities and deficits in episodic memory, both of which have been consistently reported in psychiatric disorders (Bora et al, 2009, 2013; Bourne et al, 2013; Lim et al, 2013; Szöke et al, 2008).

In the case of $\mathrm{BD}$, psychotropic treatment may influence telomere length. There is convincing evidence that patients on long-term lithium treatment have longer telomeres (Martinsson et al, 2013; Squassina et al, 2016), whereas the case regarding antidepressants remains equivocal (Verhoeven et al, 2017; Bersani et al, 2015; Soeiro-de-Souza et al, 2014). The relationship between telomere length and $\mathrm{BD}$ is therefore complex, implicating both disease- and treatment-related mechanisms. One way to disentangle these effects is to examine first-degree relatives of patients, as telomere length shows high heritability (Slagboom et al, 1994). Accordingly, we examined telomere length in remitted patients with $\mathrm{BD}$, first-degree relatives of patients, and unrelated healthy comparison individuals. We further investigated the effect of psychotropic treatment on telomere length and the association between telomere length with hippocampal volume and episodic memory.

\section{MATERIALS AND METHODS}

Buccal DNA was available from 217 individuals of white British ancestry who had participated in the Vulnerability to Bipolar Disorders Study (VIBES), described previously (Delvecchio et al, 2015; Dima et al, 2013, 2016; Forcada et al, 2011; Frangou, 2009,2011; Jogia et al, 2011, 2012; Kempton et al, 2009; Lelli-Chiesa et al, 2011; Perrier et al, 2011; Pompei et al, 2011a, b; Ruberto et al, 2011; Takahashi et al, 2010). The VIBES sample includes (1) patients who fulfill criteria for BD-I based on the Diagnostic and Statistical Manual of Mental Disorders, 4th edition, revised (DSM-IV) (American Psychiatric Association, 1994) (2) first-degree relatives and, (3) unrelated healthy individuals without a personal or family history of psychiatric disorders. Patients and relatives were screened to exclude pedigrees with schizophrenia or schizophrenia spectrum disorders. Exclusion criteria for all participants were current and hereditary neurological disorders, DSM-IV lifetime drug or alcohol dependence or drug or alcohol abuse in the preceding 6 months, and contraindications to magnetic resonance imaging (MRI). Trained psychiatrists and clinical psychologists respectively conducted clinical interviews and cognitive assessments. Diagnostic assessments were based on the Structured Clinical Interview for DSM-IV disorders (First et al, 2002a, b) and psychopathology was rated using the Hamilton Depression Rating Scale (HDRS; Hamilton, 1960) and the Young Mania Rating Scale (YMRS; Young et al, 1978). The study received institutional ethical approval. All individuals provided written informed consent before participation.

The study sample comprised 63 patients with BD, 74 firstdegree relatives (siblings $=35$; offspring $=39$ ), and 80 unrelated healthy volunteers (Table 1 and Supplementary Tables S1 and S2); 27 patients with BD and 8 relatives were unrelated to any other participant in the database. Of the first-degree relatives, 21 had a lifetime diagnosis of MDD and 4 of Anxiety Disorders (Supplementary Table S1). All participants with psychiatric diagnoses were in remission at the time of study enrolment defined as a HDRS and YMRS score below 7 (Table 1), in accordance with the criteria set by the task force of International Society for Bipolar Disorders (Tohen et al, 2009). All but 4 patients with BD were medicated as detailed in Table 1 . In addition, 15 of the 25 relatives with non-BD psychiatric diagnoses were prescribed antidepressants as monotherapy at the time of study participation (Table 1). Relatives with non-BD diagnoses who were not on treatment had been either medication naive $(n=7)$ or had not received any psychotropic treatment for $>1$ year.

\section{Cognitive Assessment}

In all participants, an estimate of general intellectual ability was obtained using the Wechsler Adult Intelligence ScaleRevised (Wechsler, 1981) and episodic memory was assessed using verbal paired associates (VPA) test from the Wechsler Memory Scale-Third Edition (Wechsler, 1997). This is the most widely used instrument for the assessment of hippocampus-linked memory (Van Petten, 2004). Scaled scores for VPA-immediate and VPA-delayed recall were used in the analyses.

Determination of telomere length. Buccal DNA was extracted using a standardized procedure (Freeman et al, 2003). DNA samples had good purity ratios (260/280 ratios between 1.7 and 1.9), as measured using the Nanodrop, ND1000 (Thermoscientific, Wilmington, DE). Telomere length was quantified using quantitative real-time PCR (qPCR) assays as previously described (Cawthon, 2009; Vincent et al, 2017) performed on the ABI Prism 7900HT Sequence Detection System, with the output generated using SDS Software version 2 (details in Supplementary Material and Supplemental Figure S1). Telomere lengths are reported as relative ratios of the copy number of telomere DNA (TTAGGG) to a single-copy gene (albumin). The telomere length was normally distributed in the entire sample (Kolmogorov-Smirnov $p=0.09$ ). Eleven specimens were excluded because they either failed quality control $(n=4)$ or were identified as outliers $(n=7)$ (telomere length $>2$ $\mathrm{SD})$. The telomere length was negatively associated with age in the entire sample $(\beta=-0.18 ; t=-2.72 ; p=0.007)$ but not with sex $(\beta=0.07 ; t=1.09 ; p=0.29)$. Further analyses showed that the regression slopes were not statistically different by sex or diagnostic group as detailed in Supplementary Material (Supplementary Figure S2 and Supplementary Tables S3-S5). Following linear regression of age and sex, the standardized residuals of the telomere length, referred to as age- and sex-adjusted telomere length, were used in most downstream analyses.

\section{MR Imaging}

High-resolution T1-weighted whole-brain MR images were obtained on a GE Signa HD 1.5T MR imaging system using an inversion recovery prepared, spoiled gradient-echo sequence. Whole-brain coverage was obtained in axial orientation with slice thickness of $1.5 \mathrm{~mm}$, repetition time of $18 \mathrm{~ms}$, echo time of $5.1 \mathrm{~ms}$, flip angle of $20^{\circ}$, field of view $=240 \times 180 \mathrm{~mm}$, and voxel dimensions $=0.9375 \times 0.9375 \times 1.5 \mathrm{~mm}$. Following 
preprocessing, we used FreeSurfer, version 5.3.0 (http://surfer. nmr.mgh.harvard.edu/), a widely used and validated software, to segment and respectively quantify total intracranial and left and right hippocampal volume. Segmented regions were visually inspected and statistically evaluated for outliers.

\section{Statistical Analysis}

Group differences were examined using analysis of variance (followed by post hoc tests) and independent $t$-tests, as appropriate. Family membership was modeled as a repeated measure. Bivariate associations were assessed using Spearman's correlation coefficient and regression analyses were used to model the contribution of multiple predictors. We first examined the effect of potential confounders, namely medication in patients and the relatives and the effect of psychiatric status (with regard to non-BD diagnoses) in the relatives to determine the number of groups and variables to be considered. Analyses were performed in SPSS (Version 22, IBM, New York, NY).

\section{RESULTS}

\section{Examination of Confounders}

Telomere length and medication in patients with BD. Details on medication are shown in Table 1. In patients with $\mathrm{BD}$, the mean duration of treatment with lithium was 3.8 years (range: 6 months to 40 years) and the mean dose was $904 \mathrm{mg}$ (range 600-1200 mg). Lithium dose and treatment duration did not correlate with telomere length $(p>0.13)$. Lithium treatment status was not associated with differences in age of onset, or HDRS and YMRS scores $(p>0.94)$. Only four patients with BD who were not on current treatment with lithium had been prescribed this medication at some point in the past.

We then examined the effect of medication (on lithium vs not on lithium, on antidepressants $v s$ not on antidepressants; typical antipsychotic, atypical antipsychotic, none; carbamazepine, lamotrigine, sodium valproate, none) on age- and sex-adjusted telomere length in patients with $\mathrm{BD}$. We first tested the effect of each individual class and then considered all classes together. Treatment with lithium was associated with longer telomeres $\left(t_{60}=-2.24, p=0.03\right)$. We found no effect of antidepressants $\left(t_{60}=1.13, p=0.16\right)$, antipsychotics $\left(\mathrm{F}_{2,60}=0.57, p=0.57\right)$, or anticonvulsants $\left(\mathrm{F}_{3,60}=1.69\right.$, $p=0.15)$. When all medications and their interactions were considered, there was still an overall effect of lithium $\left(\mathrm{F}_{1}=4.01, p=0.04\right)$, but the main effects and interactions with the other medication classes were not significant $(p>0.22)$.

Telomere length and medication in relatives of patients with $B D$. Relatives had only been exposed to antidepressants. A multiple regression analysis did not support an association between telomere length and antidepressant treatment $(\beta=-0.02, t=-0.33 ; p=0.73)$ in relatives; in the same model we found a significant association with age $(\beta=-0.19, t=-2.37 ; p=0.01)$ but not sex $(\beta=0.10, t=1.32$; $p=0.18)$. Moreover, age-and sex-adjusted telomere length did not differ between relatives based on their antidepressant exposure $\left(F_{1,63}=1.79, p=0.18\right)$. Further analyses on the association between antidepressants and telomere length can be found in Supplementary Material.

Telomere length and psychiatric status in relatives of patients with BD. Age- and sex-adjusted telomere length differed between relatives with psychiatric diagnoses, psychiatrically well relatives, and healthy volunteers $\left(\mathrm{F}_{2,154}=4.24\right.$, $p=0.01)$. The post hoc Bonferroni corrected pairwise tests showed that healthy relatives had significantly shorter telomere length than healthy volunteers $(p=0.02)$, whereas no other pairwise comparison was significant $(p>0.20)$.

\section{Primary Analyses}

Having established which confounders were relevant, we proceeded to carry out a series of hypothesis-driven analyses.

Telomere length in patients with $B D$ and first-degree relatives. Based on the results above we considered five groups in our final analysis, namely, unrelated healthy participants, psychiatrically well relatives, relatives with psychiatric diagnoses, patients with $\mathrm{BD}$ on lithium, and patients with BD not on lithium. We found an overall effect of group on age- and sex-adjusted telomere length $\left(\mathrm{F}_{4,217}=3.79, p=0.005\right)$. The post hoc Bonferroni corrected pairwise tests showed that compared with unrelated healthy participants, telomere length was shorter in psychiatrically well relatives $(p=0.007$; Figure 1) and relatives with psychiatric diagnoses, although at nominal statistical significance $(p=0.07)$. Lithium-treated patients with $\mathrm{BD}$ had longer telomere length compared with psychiatrically well relatives $(p=0.001)$, relatives with psychiatric diagnoses $(p=0.01)$, and patients with $\mathrm{BD}$ not on lithium $(p=0.02)$; all other pairwise comparisons were not significant.

Telomere length and hippocampal volume. The mean and $\mathrm{SD}$ of the hippocampal volumes are shown in Table 1 and Supplementary Table S10. There was no effect of group (ie, healthy volunteers, psychiatrically well relatives, relatives with psychiatric diagnoses, patients with $\mathrm{BD}$ on lithium,

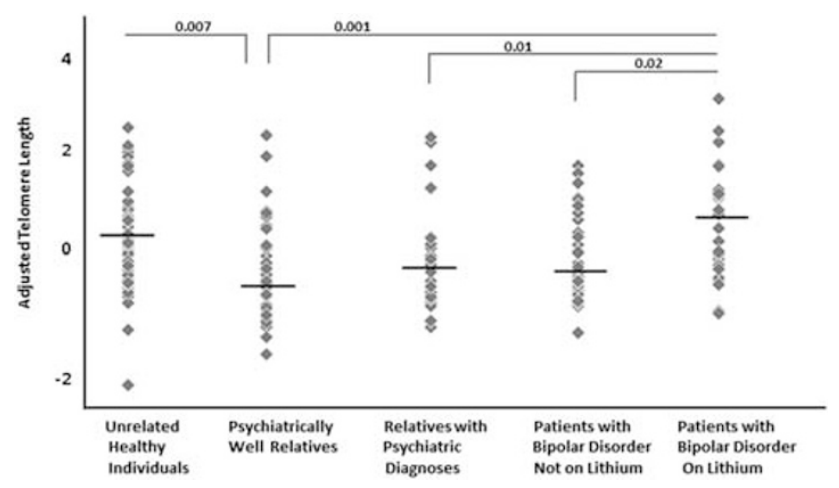

Figure I Scatterplot showing the distribution of adjusted telomere length in the study sample. Compared with unrelated healthy individuals, age- and sex-adjusted telomere length was shorter in psychiatrically well relatives and in relatives with psychiatric diagnoses relative to controls $(p=0.07$; not shown in figure). Lithium-treated patients with $\mathrm{BD}$ had longer telomere length compared with relatives, regardless of psychiatric status, and patients with BD not on lithium. 
patients with $\mathrm{BD}$ not on lithium) on intracranial volume (ICV) $\left(\mathrm{F}_{2,162}=0.98, p=0.37\right)$ and no effect of age $\left(F_{1,162}=0.59, p=0.44\right)$ but a significant effect of sex $\left(\mathrm{F}_{1,162}=4.48, p=0.03\right)$. There was no significant effect of group on hippocampal volumes (left $\mathrm{F}_{4,173}=0.81, p=0.51$; right $\mathrm{F}_{4,173}=1.59, p=0.17$ ); the effects of age and sex were significant $(p<0.001)$ but not the group $\times$ sex $\times$ age interaction $(p>0.50)$. We found no significant correlation between hippocampal volumes and lithium dose or duration of lithium treatment $(p>0.14)$ in patients with $\mathrm{BD}$; we found no significant correlation between hippocampal volumes and antidepressant treatment in patients with $\mathrm{BD}$ or relatives $(p>0.14)$.

We found no difference in the slopes between telomere length and left and right hippocampal volumes with respect to group (Supplementary Figures S3 and S4 and Supplementary Tables S6 and S7) or sex (Supplementary Figures S5 and S6 and Supplementary Tables S8 and S9). Telomere length explained a substantial amount of the variance of the left (adjusted $R^{2}=0.21, \beta=0.46, p<0.001$, 95\% confidence intervals: $0.32-0.58$ ) and right (adjusted $R^{2}=0.22, \quad \beta=0.47, \quad p<0.001,95 \%$ confidence intervals: 0.31-0.56) hippocampal volume (Figure 2).

Telomere length and episodic memory. The mean and SD of the memory variables are shown in Table 1 . There was no significant main effect of group (healthy volunteers, psychiatrically well relatives, relatives with psychiatric diagnoses, patients with $\mathrm{BD}$ on lithium, patients with $\mathrm{BD}$ not on lithium $)$ on IQ $\left(\mathrm{F}_{4,184}=2.36, p=0.20\right)$. There was a significant effect of group on VPA-immediate recall $\left(\mathrm{F}_{4,184}=2.59, p=0.04\right)$. Nonlithium-treated patients with $\mathrm{BD}(p=0.008)$ and relatives with psychiatric diagnoses performed worse than healthy volunteers $(p=0.05)$. Similarly, there was a significant main effect of group on VPAdelayed recall $\left(\mathrm{F}_{4,184}=8.51, p<0.001\right)$. Compared with unrelated healthy volunteers, delayed recall was reduced in psychiatrically well relatives $(p<0.001)$, relatives with psychiatric diagnoses $(p<0.001)$, and nonlithium-treated patients with $\mathrm{BD}(p=0.05)$.

We found no difference in the slopes between telomere length and VPA-immediate and VPA-delayed recall with respect to group (Supplementary Figures S7 and S9 and Supplementary Tables S11 and S13) or sex (Supplementary Figures S8 and S10 and Supplementary Tables S12 and S14). Telomere length explained a nonsignificant amount of the variance in VPA-immediate recall (adjusted $R^{2}=0.004$; $\beta=0.09 ; p=0.19,95 \%$ confidence intervals: $-0.26,1.31)$. Telomere explained a small but significant amount of the variance for VPA-delayed recall (adjusted $R^{2}=0.020$; $\beta=0.14, p=0.05 ; 95 \%$ confidence intervals: $-0.003,1.25$ ) (Figure 2).

Telomere length and clinical features. We examined correlations between age- and sex-adjusted telomere length and severity of manic and depressive psychopathology, number of episodes (total, manic, depressive, mixed), and age of onset. None was significant $(\rho<0.15, p>0.10)$.

\section{DISCUSSION}

This is the first study to date to demonstrate a link between shorter telomere length and familial risk for BD. Lithium treatment was associated with telomere length such that patients on long-term lithium treatment had longer telomeres compared with relatives and patients with $\mathrm{BD}$ who were not treated with lithium. In the entire sample, telomere length was also associated with larger hippocampal volume and better episodic memory.

Our results suggest that shorter telomere length may be a common factor linking genetic liability to BD to multisystem disorder vulnerability. Shorter telomeres have been associated with multiple adverse health outcomes, primarily cardiovascular disease (Brouilette et al, 2003; D'Mello et al, 2015; Fitzpatrick et al, 2007; O’Donnell et al, 2008), type 2 diabetes (O’Donnell et al, 2008), age-related cognitive dysfunction (Yaffe et al, 2011), and dementia (Panossian et al, 2003; Thomas et al, 2008). Comorbidities such as hypertension, elevated lipids, poor glycemic control, and diabetes type 2 are more prevalent in patients with $\mathrm{BD}$ compared with the general population (Beyer et al, 2005; Czepielewski et al, 2013; Fiedorowicz et al, 2010; Forty et al, 2014; McIntyre et al, 2006, 2010; Smith et al, 2013). Although psychotropic medication may contribute to physical morbidity, cardiometabolic disturbances in patients with $\mathrm{BD}$ have been observed independent of medication exposure (Maina et al, 2008; Regenold et al, 2002). Medical morbidity in relatives of patients with $\mathrm{BD}$ is understudied, but according to a recent study, 26\% of first-degree relatives of patients with $\mathrm{BD}$ self-reported a cardiometabolic disorder as compared with $13 \%$ of individuals without a family history of psychiatric disorders (Mothi et al, 2015). Patients with BD are also at greater risk of developing dementia later in life compared with patients with nonpsychiatric disorders
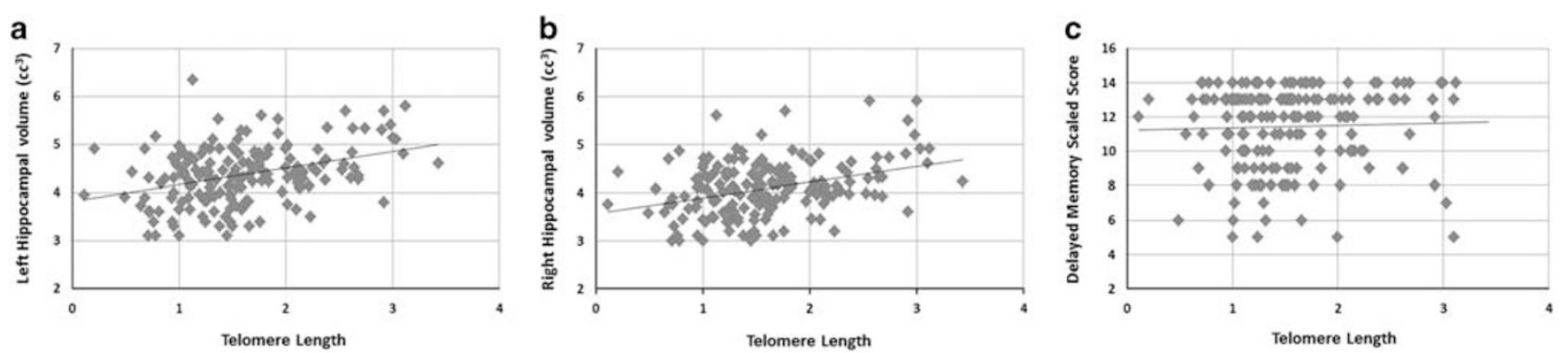

Figure 2 Scatterplot of the association between telomere length, hippocampal volume, and delayed memory in the study sample. In the entire sample, telomere length was positively associated with left (a) and (b) right hippocampal volume and with (c) delayed recall in the verbal paired associates test. 
(da Silva et al, 2013; Kessing and Nilsson, 2003) but this association has not been examined in first-degree relatives.

Telomere length was shorter in first-degree relatives compared with unrelated healthy comparison individuals, potentially reflecting the cumulative lifetime burdens of genetic and environmental exposures. Although shorter telomere length has been linked to insufficient telomerase activity (Blackburn, 1991; Lu et al, 2013), large populationbased studies suggest individuals with shorter telomeres (Epel et al, 2008; Farzaneh-Far et al, 2010), including those individual experiencing significant distress (Damjanovic et al, 2007), may have upregulated telomerase that maintains telomere length. Telomerase activity has not been assessed in individuals with familial risk for $\mathrm{BD}$, but in patients longer telomere length has been associated with lithium-induced increase in telomerase activity (Martinsson et al, 2013; Wei et al, 2015; Squassina et al, 2016). Alternatively, longer telomere length in $\mathrm{BD}$ may be predictive of good lithium response and hence long-term lithium treatment. The crosssectional nature of the current study does not allow us to resolve the direction of causality. We did not find evidence that antidepressants influence telomere length in patients with $\mathrm{BD}$ or their relatives, consistent with the lack of such an association reported in larger studies (Verhoeven et al, 2017).

We confirmed previously reported associations between telomere length, hippocampal volume (King et al, 2014; Nilsonne et al, 2015), and episodic memory (Valdes et al, 2005) that support the notion that telomere length is a marker of hippocampal vulnerability linked to reduced cell proliferation potential (Wolkowitz et al, 2015). Reduction in proliferative potential is likely to affect primarily cells capable of division in the adult brain; these would include neural stem cells located in the dentate gyrus (Gage et al, 1995; Palmer et al, 1997) and other cells that support neuronal function (eg, microglia, astrocytes, oligodendrocytes, and pericytes). In preclinical studies, telomerase induction has been shown to reverse tissue degeneration (Jaskelioff et al, 2011; Shingu et al, 2015) and restore proliferative potential of neuronal progenitor cells (Jaskelioff et al, 2011) that may account for the association between lithium treatment and decreased risk of developing dementia in patients with $\mathrm{BD}$ (da Silva et al, 2013; Kessing et al, 2008).

There are several methodological considerations pertinent to this study. Telomere length was ascertained from buccal rather than brain tissue. However, previous studies have found that this is an acceptable surrogate as genetic influences on the regulation of telomere length appear tissue independent (Dlouha et al, 2014; Friedrich et al, 2000). We conducted a number of analyses to estimate and subsequently model the contribution of potential confounding (eg, medication) and moderating variables (eg, age). No correction for multiple comparisons was applied to these analyses as the intention was to identify all potential sources of variance in this data set and account for them in hypothesis testing. The results of our hypothesis-driven analyses survive Bonferroni correction. Medication adherence was based on participants' self-report. We considered these reports largely valid given that patients had remained on their prescribed medication for long periods and were in remission at study entry. As telomere length changes over time, longitudinal designs are critical in delineating the trajectories of change. However, general population samples have found no evidence of accelerated telomere shortening over follow-up periods of 5-10 years in people with depression or anxiety disorders (Hoen et al, 2011; Verhoeven et al, 2016, 2017). Telomere shortening has been associated with adversity (Epel et al, 2004; Gianaros et al, 2007; Shalev et al, 2013), oxidative stress and inflammation (Masi et al, 2012; O'Donovan et al, 2011; Saretzki and Von Zglinicki, 2002), insulin resistance and type 2 diabetes (Demissie et al, 2006), obesity, and smoking (Valdes et al, 2005). In addition, telomere length may also be influenced by other genetic risk factors for $\mathrm{BD}$. Examination of the complex interface between these factors, telomere length, and $\mathrm{BD}$ in longitudinal studies will further enrich our understanding of the biological mechanisms involved.

To our knowledge, this study provides the first evidence linking telomere length to familial propensity to $\mathrm{BD}$. An increased understanding of telomere biology may lead to potential therapeutic interventions to maintain telomere length or reverse telomere attrition. In clinical practice, it would be advisable to target modifiable risk factors such as smoking, obesity, and stress and promote protective factors relating to healthy lifestyle and physical activity (Cherkas et al, 2008). Furthermore, targeting telomerase or other associated proteins may provide novel pharmacological targets that could address both mental and physical morbidity in those predisposed to or suffering from BD.

\section{FUNDING AND DISCLOSURE}

The authors declare no conflict of interest.

\section{ACKNOWLEDGMENTS}

Dr Frangou was partially funded by the National Institutes of Mental Health (R01-MH104284-01A1). Drs Powell, Dima, and Breen and the laboratory work were supported in part by the NIHR Biomedical Research Centre ('BRC') and NIHR Dementia Biomedical Research Unit ('BRU') hosted at King's College London and South London and Maudsley NHS Foundation Trust and funded by the National Institute for Health Research under its Biomedical Research Centres funding initiative. The views expressed are those of the authors and not necessarily those of the BRC or the BRU, the NHS, the NIHR, or the Department of Health. Additional support was provided by the Psychiatry Research Trust grant (Grant Reference: 92 Branthwaite; Drs Powell and Dima), the Brain Behavior Foundation (Leichtung Family Investigator, Grant ID: 22471; Dr Dima). Dr Breen has received research grant funding from Eli Lilly. Dr. Powell currently holds a Medical Research Council Skills Development Fellowship (MR/N014863/1).

\section{REFERENCES}

Allsopp RC, Vaziri H, Patterson C, Goldstein S, Younglai EV, Futcher $\mathrm{AB}$ et al (1992). Telomere length predicts replicative capacity of human fibroblasts. Proc Natl Acad Sci USA 89: 10114-10118.

American Psychiatric Association (1994). Diagnostic and Statistical Manual of Mental Disorders, 4th edn. American Psychiatric Press: Washington, DC. 
Barbé-Tuana FM, Parisi MM, Panizzutti BS, Fries GR, Grun LK, Guma FT et al (2016). Shortened telomere length in bipolar disorder: a comparison of the early and late stages of disease. Rev Bras Psiquiatr 38: 281-286.

Barnes J, Bartlett JW, van de Pol LA, Loy CT, Scahill RI, Frost C et al (2009). A meta-analysis of hippocampal atrophy rates in Alzheimer's disease. Neurobiol Aging 30: 1711-1723.

Bersani FS, Lindqvist D, Mellon SH, Penninx BW, Verhoeven JE, Révész D et al (2015). Telomerase activation as a possible mechanism of action for psychopharmacological interventions. Drug Discov Today 20: 1305-1309.

Beyer J, Kuchibhatla M, Gersing K, Krishnan KR (2005). Medical comorbidity in a bipolar outpatient clinical population. Neuropsychopharmacology 30: 401-404.

Blackburn EH (1991). Structure and function of telomeres. Nature 350: $569-573$.

Bora E, Harrison BJ, Yücel M, Pantelis C (2013). Cognitive impairment in euthymic major depressive disorder: a metaanalysis. Psychol Med 43: 2017-2026.

Bora E, Yucel M, Pantelis C (2009). Cognitive endophenotypes of bipolar disorder: a meta-analysis of neuropsychological deficits in euthymic patients and their first-degree relatives. J Affect Disord 113: 1-20.

Bourne C, Aydemir Ö, Balanzá-Martínez V, Bora E, Brissos S, Cavanagh JT et al (2013). Neuropsychological testing of cognitive impairment in euthymic bipolar disorder: an individual patient data meta-analysis. Acta Psychiatr Scand 128: 149-162.

Brouilette S, Singh RK, Thompson JR, Goodall AH, Samani NJ (2003). White cell telomere length and risk of premature myocardial infarction. Arterioscler Thromb Vasc Biol 23: 842-846.

Calado RT, Young NS (2009). Telomere diseases. N Engl J Med 361: 2353-2365.

Cawthon RM (2009). Telomere length measurement by a novel monochrome multiplex quantitative PCR method. Nucleic Acids Res 37: e21.

Cherkas LF, Hunkin JL, Kato BS, Richards JB, Gardner JP, Surdulescu GL et al (2008). The association between physical activity in leisure time and leukocyte telomere length. Arch Intern Med 168: 154-158.

Colpo GD, Leffa DD, Köhler CA, Kapczinski F, Quevedo J, Carvalho AF (2015). Is bipolar disorder associated with accelerating aging? A meta-analysis of telomere length studies. J Affect Disord 186: 241-248.

Czepielewski L, Filho LD, Brietzke E, Grassi-Oliveira R (2013). Bipolar disorder and metabolic syndrome: a systematic review. Rev Bras Psiquiatr 35: 88-93.

Damjanovic AK, Yang Y, Glaser R, Kiecolt-Glaser JK, Nguyen H, Laskowski B et al (2007). Accelerated telomere erosion is associated with a declining immune function of caregivers of Alzheimer's disease patients. J Immunol 179: 4249-4254.

Darrow SM, Verhoeven JE, Révész D, Lindqvist D, Penninx BW, Delucchi KL et al (2016). The association between psychiatric disorders and telomere length: a meta-analysis involving 14,827 persons. Psychosom Med 78: 776-787.

da Silva J, Gonçalves-Pereira M, Xavier M, Mukaetova-Ladinska EB (2013). Affective disorders and risk of developing dementia: systematic review. Br J Psychiatry 202: 177-186.

Delvecchio G, Dima D, Frangou S (2015). The effect of ANK3 bipolar-risk polymorphisms on the working memory circuitry differs between loci and according to risk-status for bipolar disorder. Am J Med Genet B Neuropsychiatr Genet 168B: 188-196.

Demissie S, Levy D, Benjamin EJ, Cupples LA, Gardner JP, Herbert A et al (2006). Insulin resistance, oxidative stress, hypertension, and leukocyte telomere length in men from the Framingham Heart Study. Aging Cell 5: 325-330.

Dickerson BC, Eichenbaum H (2010). The episodic memory system: neurocircuitry and disorders. Neuropsychopharmacology 35: 86-104.
Dima D, Roberts RE, Frangou S (2016). Connectomic markers of disease expression, genetic risk and resilience in bipolar disorder. Transl Psychiatry 6: e706.

Dima D, Jogia J, Collier D, Vassos E, Burdick KE, Frangou S (2013). Independent modulation of engagement and connectivity of the facial network during affect processing by CACNA1C and ANK3 risk genes for bipolar disorder. JAMA Psychiatry 70: 1303-1311.

Dlouha D, Maluskova J, Kralova Lesna I, Lanska V, Hubacek JA (2014). Comparison of the relative telomere length measured in leukocytes and eleven different human tissues. Physiol Res 63 (Suppl 3): S343-S350.

D’Mello MJJ, Ross SA, Briel M, Anand SS, Gerstein H, Paré G (2015). Association between shortened leukocyte telomere length and cardiometabolic outcomes: systematic review and metaanalysis. Circ. Cardiovasc Genet 8: 82-90.

Eitan E, Hutchison ER, Mattson MP (2014). Telomere shortening in neurological disorders: an abundance of unanswered questions. Trends Neurosci 37: 256-263.

Epel ES, Blackburn EH, Lin J, Dhabhar FS, Adler NE, Morrow JD et al (2004). Accelerated telomere shortening in response to life stress. Proc Natl Acad Sci USA 101: 17312-17315.

Epel ES, Merkin SS, Cawthon R, Blackburn EH, Adler NE, Pletcher MJ et al (2008). The rate of leukocyte telomere shortening predicts mortality from cardiovascular disease in elderly men. Aging (Albany NY) 1: 81-88.

Farzaneh-Far R, Lin J, Epel E, Lapham K, Blackburn E, Whooley MA (2010). Telomere length trajectory and its determinants in persons with coronary artery disease: longitudinal findings from the heart and soul study. PLoS ONE 5: e8612.

Fiedorowicz JG, Palagummi NM, Behrendtsen O, Coryell WH (2010). Cholesterol and affective morbidity. Psychiatry Res 175: 78-81.

First MB, Spitzer RL, Gibbon M, Williams JBW (2002a). Structured Clinical Interview for DSM-IV-TR Axis I Disorders, Research Version, Non-Patient Edition. Biometrics Research, New York State Psychiatric Institute: New York, NY.

First MB, Spitzer RL, Gibbon M, Williams JBW (2002b). Structured Clinical Interview for DSM-IV-TR Axis I Disorders, Research Version, Patient Edition. Biometrics Research, New York State Psychiatric Institute: New York, NY.

Fitzpatrick AL, Kronmal RA, Gardner JP, Psaty BM, Jenny NS, Tracy RP et al (2007). Leukocyte telomere length and cardiovascular disease in the cardiovascular health study. Am J Epidemiol 165: $14-21$.

Forcada I, Papachristou E, Mur M, Christodoulou T, Jogia J, Reichenberg A et al (2011). The impact of general intellectual ability and white matter volume on the functional outcome of patients with bipolar disorder and their relatives. J Affect Disord 130: 413-420.

Forty L, Ulanova A, Jones L, Jones I, Gordon-Smith K, Fraser C et al (2014). Comorbid medical illness in bipolar disorder. $\mathrm{Br} J$ Psychiatry 205: 465-472.

Frangou S (2009). Risk and resilience in bipolar disorder: rationale and design of the Vulnerability to Bipolar Disorders Study (VIBES). Biochem Soc Trans 37: 1085-1089.

Frangou S (2011). Brain structural and functional correlates of resilience to bipolar disorder. Front Hum Neurosci 5: 184.

Freeman B, Smith N, Curtis C, Huckett L, Mill J, Craig IW (2003). DNA from buccal swabs recruited by mail: evaluation of storage effects on long-term stability and suitability for multiplex polymerase chain reaction genotyping. Behav Genet 33: 67-72.

Friedrich U, Griese E, Schwab M, Fritz P, Thon K, Klotz U (2000). Telomere length in different tissues of elderly patients. Mech Ageing Dev 119: 89-99.

Gage FH, Coates PW, Palmer TD, Kuhn HG, Fisher LJ, Suhonen JO et al (1995). Survival and differentiation of adult neuronal progenitor cells transplanted to the adult brain. Proc Natl Acad Sci USA 25: 11879-11883. 
Gianaros PJ, Jennings JR, Sheu LK, Greer PJ, Kuller LH, Matthews KA (2007). Prospective reports of chronic life stress predict decreased grey matter volume in the hippocampus. Neuroimage 35: 795-803.

Hamilton M (1960). A rating scale for depression. J Neurol Neurosurg Psychiatry 23: 56-62.

Hartmann N, Boehner M, Groenen F, Kalb R (2010). Telomere length of patients with major depression is shortened but independent from therapy and severity of the disease. Depress Anxiety 27: 1111-1116.

Heidinger BJ, Blount JD, Boner W, Griffiths K, Metcalfe NB, Monaghan P (2011). Telomere length in early life predicts lifespan. Proc Natl Acad Sci USA 109: 1743-1748.

Hibar DP, Westlye LT, van Erp TG, Rasmussen J, Leonardo CD, Faskowitz J et al (2016). Subcortical volumetric abnormalities in bipolar disorder. Mol Psychiatry 21: 1710-1716.

Hoen PW, de Jonge P, Na BY, Farzaneh-Far R, Epel E, Lin J et al (2011). Depression and leukocyte telomere length in patients with coronary heart disease: data from the Heart and Soul Study. Psychosom Med 73: 541-547.

Jaskelioff M, Muller FL, Paik JH, Thomas E, Jiang S, Adams AC et al (2011). Telomerase reactivation reverses tissue degeneration in aged telomerase-deficient mice. Nature 469: 102-106.

Jogia J, Dima D, Kumari V, Frangou S (2012). Frontopolar cortical inefficiency may underpin reward and working memory dysfunction in bipolar disorder. World J Biol Psychiatry 13: 605-615.

Jogia J, Ruberto G, Lelli-Chiesa G, Vassos E, Maierú M, Tatarelli R et al (2011). The impact of the CACNA1C gene polymorphism on frontolimbic function in bipolar disorder. Mol Psychiatry 16: 1070-1071.

Kempton MJ, Haldane M, Jogia J, Grasby PM, Collier D, Frangou S (2009). Dissociable brain structural changes associated with predisposition, resilience, and disease expression in bipolar disorder. J Neurosci 29: 10863-10868.

Kessing LV, Nilsson FM (2003). Increased risk of developing dementia in patients with major affective disorders compared to patients with other medical illnesses. J Affect Disord 73: 261-269.

Kessing LV, Sondergard L, Forman JL, Andersen PK (2008). Lithium treatment and risk of dementia. Arch Gen Psychiatry 65: $1331-1335$

King KS, Kozlitina J, Rosenberg RN, Peshock RM, McColl RW, Garcia CK (2014). Effect of leukocyte telomere length on total and regional brain volumes in a large population-based cohort. JAMA Neurol 71: 1247-1254.

Kühn S, Gallinat J (2014). Segregating cognitive functions within hippocampal formation: a quantitative meta-analysis on spatial navigation and episodic memory. Hum Brain Mapp 35: 1129-1142.

Lelli-Chiesa G, Kempton MJ, Jogia J, Tatarelli R, Girardi P, Powell J et al (2011). The impact of the Val158Met catechol-Omethyltransferase genotype on neural correlates of sad facial affect processing in patients with bipolar disorder and their relatives. Psychol Med 41: 779-788.

Lim J, Oh IK, Han C, Huh YJ, Jung IK, Patkar AA et al (2013). Sensitivity of cognitive tests in four cognitive domains in discriminating MDD patients from healthy controls: a metaanalysis. Int Psychogeriatr 25: 1543-1557.

Lima IM, Barros A, Rosa DV, Albuquerque M, Malloy-Diniz L, Neves FS et al (2015). Analysis of telomere attrition in bipolar disorder. J Affect Disord 172: 43-47.

Lu W, Zhang Y, Liu D, Songyang Z, Wan M (2013). Telomeresstructure, function, and regulation. Exp Cell Res 319: 133-141.

Lung FW, Chen NC, Shu BC (2007). Genetic pathway of major depressive disorder in shortening telomeric length. Psychiatr Genet 17: 195-199.

Maina G, Salvi V, Vitalucci A, D'Ambrosio V, Bogetto F (2008). Prevalence and correlates of overweight in drug-naïve patients with bipolar disorder. J Affect Disord 110: 149-155.
Mamdani F, Rollins B, Morgan L, Myers RM, Barchas JD, Schatzberg $\mathrm{AF}$ et al (2015). Variable telomere length across post-mortem human brain regions and specific reduction in the hippocampus of major depressive disorder. Transl Psychiatry 5: e636.

Martinsson L, Wei Y, Xu D, Melas PA, Mathé AA, Schalling M et al (2013). Long-term lithium treatment in bipolar disorder is associated with longer leukocyte telomeres. Transl Psychiatry 3: e261.

Masi S, Nightingale CM, Day IN, Guthrie P, Rumley A, Lowe GD et al (2012). Inflammation and not cardiovascular risk factors is associated with short leukocyte telomere length in 13- to 16-year-old adolescents. Arterioscler Thromb Vasc Biol 32: 2029-2034.

McIntyre RS, Konarski JZ, Soczynska JK, Wilkins K, Panjwani G, Bouffard B et al (2006). Medical comorbidity in bipolar disorder: implications for functional outcomes and health service utilization. Psychiatr Serv 57: 1140-1144.

McIntyre RS, Danilewitz M, Liauw SS, Kemp DE, Nguyen HT, Kahn LS et al (2010). Bipolar disorder and metabolic syndrome: an international perspective. J Affect Disord 126: 366-387.

Mothi SS, Tandon N, Padmanabhan J, Mathew IT, Clementz B, Tamminga $C$ et al (2015). Increased cardiometabolic dysfunction in first-degree relatives of patients with psychotic disorders. Schizophr Res 165: 103-107.

Mouiha A, Duchesne S, Alzheimer's Disease Neuroimaging Initiative (2011). Hippocampal atrophy rates in Alzheimer's disease: automated segmentation variability analysis. Neurosci Lett 495: 6-10.

Nilsonne G, Tamm S, Månsson KN, Åkerstedt T, Lekander M (2015). Leukocyte telomere length and hippocampus volume: a meta-analysis. F1000Res 4: 1073.

O'Donnell CJ, Demissie S, Kimura M, Levy D, Gardner JP, White C et al (2008). Leukocyte telomere length and carotid artery intimal medial thickness: the Framingham Heart Study. Arterioscler Thromb Vasc Biol 28: 1165-1171.

O'Donovan A, Pantell MS, Puterman E, Dhabhar FS, Blackburn EH, Yaffe $\mathrm{K}$ et al (2011). Cumulative inflammatory load is associated with short leukocyte telomere length in the Health, Aging and Body Composition Study. PLoS ONE 6: e19687.

Palmer TD, Takahashi J, Gage FH (1997). The adult rat hippocampus contains primordial neural stem cells. Mol Cell Neurosci 8: 389-404.

Panossian LA, Porter VR, Valenzuela HF, Zhu X, Reback E, Masterman D et al (2003). Telomere shortening in $\mathrm{T}$ cells correlates with Alzheimer's disease status. Neurobiol Aging 24: 77-84.

Perrier E, Pompei F, Ruberto G, Vassos E, Collier D, Frangou S (2011). Initial evidence for the role of CACNA1C on subcortical brain morphology in patients with bipolar disorder. Eur Psychiatry 26: 135-137.

Pompei F, Dima D, Rubia K, Kumari V, Frangou S (2011a). Dissociable functional connectivity changes during the Stroop task relating to risk, resilience and disease expression in bipolar disorder. Neuroimage 57: 576-582.

Pompei F, Jogia J, Tatarelli R, Girardi P, Rubia K, Kumari V et al (2011b). Familial and disease specific abnormalities in the neural correlates of the Stroop Task in bipolar disorder. Neuroimage 56: 1677-1684.

Rabinovici GD, Seeley WW, Kim EJ, Gorno-Tempini ML, Rascovsky K, Pagliaro TA et al (2007). Distinct MRI atrophy patterns in autopsy-proven Alzheimer's disease and frontotemporal lobar degeneration. Am J Alzheimers Dis Other Demen 22: 474-488.

Regenold WT, Thapar RK, Marano C, Gavirneni S, Kondapavuluru PV (2002). Increased prevalence of type 2 diabetes mellitus among psychiatric inpatients with bipolar I affective and schizoaffective disorders independent of psychotropic drug use. J Affect Disord 70: 19-26. 
Ruberto G, Vassos E, Lewis CM, Tatarelli R, Girardi P, Collier D et al (2011). The cognitive impact of the ANK3 risk variant for bipolar disorder: initial evidence of selectivity to signal detection during sustained attention. PLoS ONE 6: e16671.

Saretzki G, Von Zglinicki T (2002). Replicative aging, telomeres, and oxidative stress. Ann NY Acad Sci 959: 24-29.

Schmaal L, Veltman DJ, van Erp TG, Sämann PG, Frodl T, Jahanshad $\mathrm{N}$ et al (2016). Subcortical brain alterations in major depressive disorder: findings from the ENIGMA Major Depressive Disorder working group. Mol Psychiatry 21: 806-812.

Shalev I, Moffit TE, Sugden K, Williams B, Houts RM, Danese A et al (2013). Exposure to violence during childhood is associated with telomere erosion from 5 to 10 years of age: a longitudinal study. Mol. Psychiatry 18: 576-581.

Shingu T, Jaskelioff M, Yuan L, Ding Z, Protopopov A, KostAlimova $\mathrm{M}$ et al (2015). Utilizing murine inducible telomerase alleles in the studies of tissue degeneration/regeneration and cancer. $J$ Vis Exp 98: 1-8.

Simon NM, Smoller JW, McNamara KL, Maser RS, Zalta AK, Pollack MH et al (2006). Telomere shortening and mood disorders: Preliminary support for a chronic stress model of accelerated aging. Biol Psychiatry 60: 432-435.

Slagboom PE, Droog S, Boomsma DI (1994). Genetic determination of telomere size in humans: a twin study of three age groups. Am J Hum Genet 55: 876-882.

Smith DJ, Martin D, McLean G, Langan J, Guthrie B, Mercer SW (2013). Multimorbidity in bipolar disorder and undertreatment of cardiovascular disease: a cross sectional study. BMC Med 11: 263.

Spalding KL, Bergmann O, Alkass K, Bernard S, Salehpour M, Huttner HB et al (2013). Dynamics of hippocampal neurogenesis in adult humans. Cell 153: 1219-1227.

Soeiro-de-Souza MG, Teixeira AL, Mateo EC, Zanetti MV, Rodrigues FG, de Paula VJ et al (2014). Leukocyte telomerase activity and antidepressant efficacy in bipolar disorder. Eur Neuropsychopharmacol 24: 1139-1143.

Squassina A, Pisanu C, Congiu D, Caria P, Frau D, Niola P et al (2016). Leukocyte telomere length positively correlates with duration of lithium treatment in bipolar disorder patients. Eur Neuropsychopharmacol 26: 1241-1247.

Stewart JA, Chaiken MF, Wang F, Price CM (2012). Maintaining the end: roles of telomere proteins in end-protection, telomere replication and length regulation. Mutat Res 730: 12-19.

Szöke A, Trandafir A, Dupont ME, Méary A, Schürhoff F, Leboyer M (2008). Longitudinal studies of cognition in schizophrenia: meta-analysis. Br J Psychiatry 192: 248-257.

Takahashi T, Walterfang M, Wood SJ, Kempton MJ, Jogia J, Lorenzetti V et al (2010). Pituitary volume in patients with bipolar disorder and their first-degree relatives. I Affect Disord 124: 256-261.

Thomas P, O'Callaghan NJ, Fenech M (2008). Telomere length in white blood cells, buccal cells and brain tissue and its variation with ageing and Alzheimer's disease. Mech Ageing Dev 129: 183-190.

Tohen M, Frank E, Bowden CL, Colom F, Ghaemi SN, Yatham LN et al (2009). The International Society for Bipolar Disorders (ISBD) Task Force report on the nomenclature of course and outcome in bipolar disorders. Bipolar Disord 11: 453-473.

Valdes AM, Andrew T, Gardner JP, Kimura M, Oelsner E, Cherkas LF et al (2005). Obesity, cigarette smoking, and telomere length in women. Lancet 366: 662-664.
Valdes AM, Deary IJ, Gardner J, Kimura M, Lu X, Spector TD et al (2010). Leukocyte telomere length is associated with cognitive performance in healthy women. Neurobiol Aging 31: 986-992.

van Erp TG, Hibar DP, Rasmussen JM, Glahn DC, Pearlson GD, Andreassen OA et al (2016). Subcortical brain volume abnormalities in 2028 individuals with schizophrenia and 2540 healthy controls via the ENIGMA consortium. Mol Psychiatry 21: 585.

Van Petten C (2004). Relationship between hippocampal volume and memory ability in healthy individuals across the lifespan: review and meta-analysis. Neuropsychologia 42: 1394-1413.

Verhoeven JE, van Oppen P, Révész D, Wolkowitz OM, Penninx BWJH (2016). Depressive and anxiety disorders showing robust, but non-dynamic, 6-year longitudinal association with short leukocyte telomere length. Am J Psychiatry 173: 617-624.

Verhoeven JE, Révész D, Picard M, Epel EE, Wolkowitz OM, Matthews KA et al (2017). Depression, telomeres and mitochondrial DNA: between- and within-person associations from a 10year longitudinal study. Mol Psychiatry doi: 10.1038/mp.2017.48 (e-pub ahead of print).

Vincent J, Hovatta I, Frissa S, Goodwin L, Hotopf M, Hatch SL et al (2017). Assessing the contributions of childhood maltreatment subtypes and depression case-control status on telomere length reveals a specific role of physical neglect. J Affect Disord 213: 16-22.

Wei YB, Backlund L, Wegener G, Mathé AA, Lavebratt C (2015). Telomerase dysregulation in the hippocampus of a rat model of depression: normalization by lithium. Int J Neuropsychopharmacol 18: pyv002.

Wechsler D (1997). Wechsler Memory Scale-Third Edition Manual. The Psychological Corporation: San Antonio, TX.

Wechsler D (1981). Manual for the Wechsler Adult Intelligence Scale-Revised. Psychological Corporation: New York.

Wolkowitz OM, Mellon SH, Lindqvist D, Epel ES, Blackburn EH, Lin J et al (2015). PBMC telomerase activity, but not leukocyte telomere length, correlates with hippocampal volume in major depression. Psychiatry Res 232: 58-64.

Yaffe K, Lindquist K, Kluse M, Cawthon R, Harris T, Hsueh WC et al (2011). Telomere length and cognitive function in community-dwelling elders: findings from the Health ABC Study. Neurobiol Aging 32: 2055-2060.

Young RC, Biggs JT, Ziegler VE, Meyer DA (1978). A rating scale for mania: reliability, validity and sensitivity. Br J Psychiatry 133: 429-435.

Yu WY, Chang HW, Lin CH, Cho CL (2008). Short telomeres in patients with chronic schizophrenia who show a poor response to treatment. J Psychiatry Neurosci 33: 244-247.

This work is licensed under a Creative Commons Attribution 4.0 International License. The images or other third party material in this article are included in the article's Creative Commons license, unless indicated otherwise in the credit line; if the material is not included under the Creative Commons license, users will need to obtain permission from the license holder to reproduce the material. To view a copy of this license, visit http://creativecommons.org/licenses/ by/4.0/

(C) The Author(s) 2018

Supplementary Information accompanies the paper on the Neuropsychopharmacology website (http://www.nature.com/npp) 